\section{PRACTICAL METHOD FOR ANALYSIS AND DESIGN OF SLENDER REINFORCED CONCRETE COLUMNS SUBJECTED TO BIAXIAL BENDING AND AXIAL LOADS}

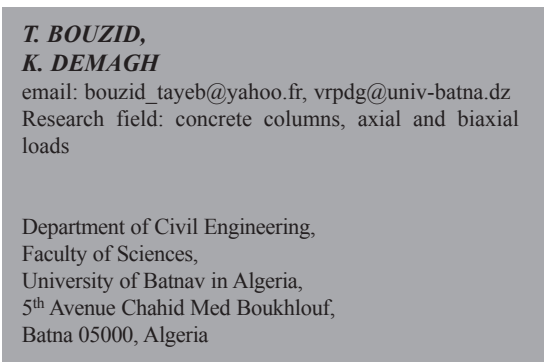

\section{KEY WORDS}

Reinforced and concrete-encased composite columns of arbitrarily shaped cross sections subjected to biaxial bending and axial loads are commonly used in many structures. For this purpose, an iterative numerical procedure for the strength analysis and design of short and slender reinforced concrete columns with a square cross section under biaxial bending and an axial load by using an EC2 stress-strain model is presented in this paper. The computational procedure takes into account the nonlinear behavior of the materials (i.e., concrete and reinforcing bars) and includes the second - order effects due to the additional eccentricity of the applied axial load by the Moment Magnification Method. The ability of the proposed method and its formulation has been tested by comparing its results with the experimental ones reported by some authors. This comparison has shown that a good degree of agreement and accuracy between the experimental and theoretical results have been obtained. An average ratio (proposed to test) of 1.06 with a deviation of $9 \%$ is achieved.
- slender,

- Bi-axial,

- bending,

- RC column,

- encased composite columns,

- composite columns.

\section{INTRODUCTION}

Reinforced and concrete-encased composite columns of arbitrarily shaped cross sections subjected to biaxial bending and an axial load are commonly used in many structures, such as buildings and bridges. A composite column is a combination of concrete, structural steel and reinforced steel to provide for an adequate load carrying capacity of the member. Such composite members can therefore provide rigidity, usable floor areas and saving for midto-tall buildings. Many experimental and analytical studies have been carried out on reinforced and composite members in the past. Furlong [1] has carried out analytical and experimental studies on reinforced concrete columns using the well-known rectangular stress block for the concrete compression zone in the analysis. Brondum-Nielsen [2] has proposed a method of calculating the ultimate strength capacity of cracked polygonal concrete sections using a rectangular stress block in the concrete compression zone of a section under biaxial bending. Hsu [3, 4] has presented theoretical and experimental results for L-shaped and channel - shaped reinforced concrete sections. Dundar [5] has studied reinforced concrete box sections under biaxial bending and an axial load. Rangan [6] has presented a method to calculate the strength of reinforced concrete slender columns, including creep deflection due to a sustained load as an additional eccentricity; the method 
compares with the ACI 318-Building Code Method [7]. Dundar and Sahin [8] have researched arbitrarily - shaped reinforced concrete sections subjected to biaxial bending and an axial load using Whitney's stress block [9] in the compression zone of a concrete section. Rodriguez and Ochoa [10] and Fafitis [11] have suggested numerical methods for the computation of the failure surface of reinforced concrete sections of an arbitrary shape. Hong [12] has proposed a simple approach for estimating the strength of slender reinforced concrete columns with an arbitrarily - shaped cross section using a nonlinear stress-strain relationship for the materials. Saatcioglu and Razvi [13] have presented experimental research that investigates the behavior of high - strength concrete columns confined by a rectilinear reinforcement under concentric compression. Furlong, et al. [14] have examined several design procedures for an ultimate strength analysis of reinforced concrete columns and compared a range of short and slender experimental columns under a short-term axial load and biaxial bending. Mirza [15] has examined the effects of variables such as the confinement effect, the ratio of structural steel to a gross area, the compressive strength of concrete, the yield strength of steel and the slenderness ratio, on the ultimate strength of composite columns. Lachance [16], Chen, et al. [17] and Sfakianakis [18] have proposed a numerical analysis method for short composite columns with an arbitrarily - shaped cross section. The confinement provided by lateral ties increases the ultimate strength capacity and ductility of reinforced concrete columns under combined biaxial bending and an axial load. The gains in strength and ductility in concrete are obtained by many confinement parameters, e.g., the compressive strength of the concrete, the longitudinal reinforcement, the type and the yield strength of the lateral ties, the tie spacing, etc. Due to such parameters, a determination of the mechanical behavior of confined concrete is not as easy as that with unconfined concrete. Some researchers, for instance, Kent and Park [19], Sheikh and Uzumeri [20], Saatcioglu and Razvi [21], Chung, et al. [22] have presented a stress-strain relationship to describe the confined concrete's behavior. Dundar, et al. [23] have carried out an experimental investigation of the behavior of reinforced concrete columns, and a theoretical procedure for an analysis of both short and slender reinforced and composite columns with an arbitrarily - shaped cross section subjected to biaxial bending and an axial load is presented. In the proposed procedure, nonlinear stress-strain relations are assumed for concrete, reinforced steel and structural steel materials. The compression zone of the concrete section and the entire section of the structural steel are divided into an adequate number of segments in order to use various stress-strain models for the analysis. The slenderness effect of the member is taken into account by using the Moment Magnification Method (MMM). The test results were compared with the theoretical results obtained by a developed computer program which uses various stress-strain models for the confined or unconfined concrete in the compression zone of the member. The comparison shows a good degree agreement of the results obtained by the proposed procedure.

The main objective of this paper is to present an iterative computing procedure for the rapid design and ultimate strength analysis of a square cross-section for both short and slender reinforced concrete elements subjected to biaxial bending and an axial load. For this aim a simple model has been developed, which considers various unconfined concrete stress-strain models for a concrete compression zone for both short and slender reinforced concrete columns. A simple formula to predict the resistance capacity of biaxially loaded short reinforced concrete columns with a square cross-section is introduced. Based on a numerical analysis, a capacity factor which represents the ratio of $\mathrm{P}-\mathrm{M}$ interaction diagrams in a uniaxial loading column to a biaxial loading column is proposed. The relationships between the capacity factor $(\mathrm{K})$ and all the design variables are established by regression, and the required P-M interaction diagram of the biaxial RC column can be easily constructed without conducting refined analyses. The slenderness effect of the member is then taken into account using the Moment Magnification Method. Finally, the theoretical results obtained from using the proposed model is compared with the theoretical and experimental results available in the literature for short and slender columns.

\section{ANALYTIC METHOD}

\subsection{Assumptions}

The proposed method is based on the following assumptions:

1. The plane sections remain plane after any deformation (Bernoulli's assumption).

2. Arbitrary monotonic stress-strain relationships for each of the three materials (i.e., concrete, structural steel and the reinforcing bars) may be assumed.

3. The longitudinal reinforcing bars are identical in diameter and are subjected to the same amount of strain as the adjacent concrete.

4. The effect of creep and the tensile strength of concrete and any direct tension stresses due to shrinkage, etc., are ignored.

5. Shear deformation is ignored.

\subsection{Stress-strain models for the materials}

The analysis utilizes well established models for concrete (confined, and unconfined) and reinforcing steel. Figure 1 and 2 show the stress strain models for the concrete and steel. 

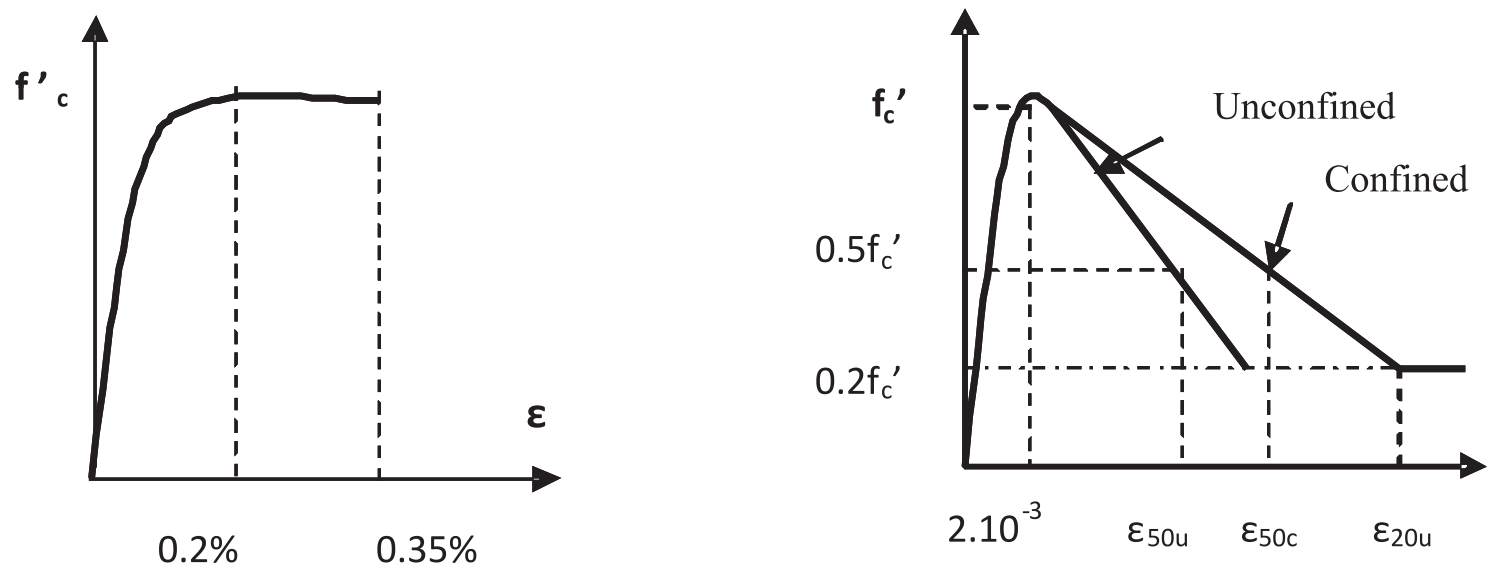

Fig. 1 Stress- strain relationship of confined and unconfined concrete in compression.

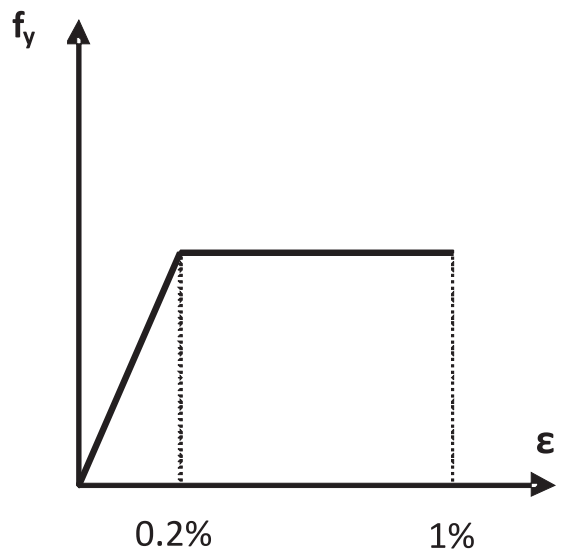

Fig. 2 Elastic-Plastic bilinear behavior for steel.

\subsection{Capacity Factor}

Since the ultimate resisting capacity of an RC column is governed by many variables and is gradually reduced as the degree of axial load increases $\left(\mathrm{P} / \mathrm{A}_{\mathrm{g}} \mathrm{f}_{\mathrm{c}}{ }_{\mathrm{c}}\right)$, it is necessary in many cases to conduct a refined numerical analysis that considers the material nonlinearities in order to accurately predict the ultimate strength of a biaxial RC column. In order to analyse and design (directly) biaxial RC columns, a capacity factor $\mathrm{K}$, which represents the ratio of the $\mathrm{P}-\mathrm{M}$ interaction diagrams in an uniaxial loading column to a biaxial loading column, is introduced. If the dimensions of the concrete cross-section and the material properties have been selected, the interaction diagrams for uniaxial loading are then easily constructed by introducing the capacity factor $(\mathrm{K})$. One can easily obtain the interaction diagrams for biaxial loading with any angle of a resultant bending moment $\mathrm{M}_{\mathrm{BIA}}$. The strength capacity factor (SCF) is defined as the ratio of the distance from the origin (eccentricity) for a uniaxial interaction diagram to a biaxial loading interaction diagram at the same degree of axial load level $\left(\mathrm{P} / \mathrm{P}_{0}\right)$, Fig. 2:

$\mathrm{P}_{\mathrm{UNI}}=\mathrm{P}_{\mathrm{BIA}}$

$\mathrm{M}_{\mathrm{UNI}}=\mathrm{K} \cdot \mathrm{M}_{\mathrm{BIA}}=\mathrm{K} \cdot \mathrm{M}_{\mathrm{n}}=\mathrm{K} \sqrt{M_{x}{ }^{2}+M_{y}{ }^{2}}$

$K=\left(\frac{O A}{O B}\right)=\frac{M_{\mathrm{UNI}}}{M_{\mathrm{BIA}}}$

Where $\mathrm{K}$ is the Capacity factor, $\mathrm{M}_{\mathrm{UNI}}$ is the equivalent uniaxial moment, and $\mathrm{M}_{\mathrm{BIA}}$ is the resultant moment for the biaxial loading.

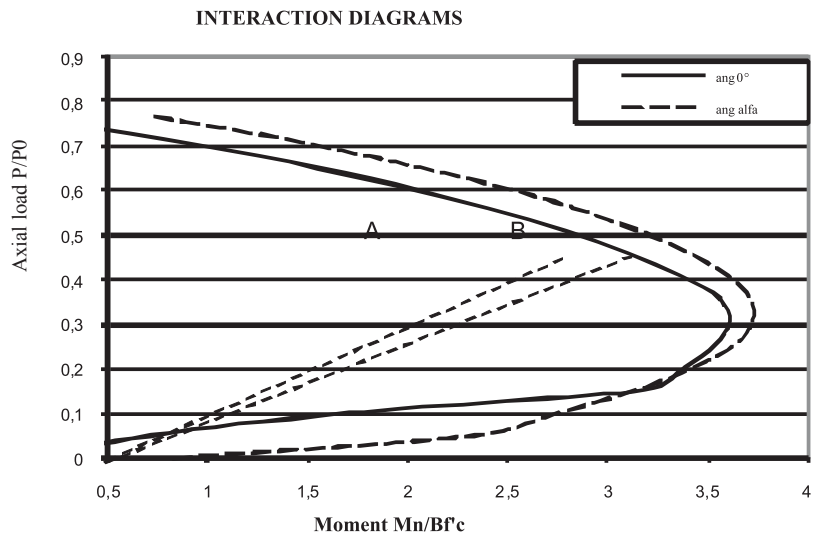

Fig. 3 Determination of the strength resistance factor $K$. 
Tab. 1 Parameters variation.

\begin{tabular}{|l|l|}
\hline Parameters & Values \\
\hline Cross-section shape & Square \\
\hline $\begin{array}{l}\text { Biaxial bending angle }(\alpha) \text { with } \\
\text { respect to a strong axis }\end{array}$ & $\alpha=0^{\circ}, 15^{\circ}, 30^{\circ}, 45^{\circ}$ \\
\hline Reinforcement distribution & Uniformly distributed at four faces \\
\hline Axial load $\mathrm{P} / \mathrm{P}_{0}$ where $\mathrm{P}_{0}=f^{\prime}{ }_{\mathrm{c}} \mathrm{A}_{\mathrm{g}}$ & $\mathbf{1 0}$ values from $\mathbf{0 , 1}_{\mathbf{0}}$ to $\mathbf{0 , 7}_{\mathbf{0}}$ \\
\hline Compressive concrete strength & $f^{\circ}{ }_{\mathrm{c}}=25,30,40 \mathrm{MPa}$ \\
\hline Steel strength & $f_{\mathrm{y}}=400 \mathrm{Mpa}$ \\
\hline Geometric reinforcement ratio & $\rho_{\mathrm{s}}=1 \%, 2 \%, 4 \%$ \\
\hline
\end{tabular}

In order to introduce a formula for the capacity factor (K), some difficulties must be overcome, because the interaction diagrams must be determined for the biaxial and uniaxial cross-sections with the same design variables used by Dundar et al. [8]; moreover an infinite number of possible RC sections can be selected for the same set of external forces applied. Hence, in determining RC interaction diagrams, all the variables need to be assumed on the basis of practical limitations and the design code requirements, R.P.A.9903 [2003]. The commonly used compressive strength of concrete and stress of steel for design are $f_{c}=25,30$ and $40 \mathrm{MPa}$ for normal concrete and $\mathrm{f}_{\mathrm{y}}=400 \mathrm{MPa}$ respectively. In addition, the steel ratio ranges from $1 \%$ to $4 \%$ in the current zones. Due to the symmetry of the section and the reinforcement, the angle of loading is supposed to vary from $0^{\circ}$ (uniaxial) to $45^{\circ}$ (biaxial) with an increment of $15^{\circ}$. Table 1 gives the range of variables adopted for the design of experimental plans to be included in the analysis.

The effect of the different parameters on the interaction diagrams can be summarized as:

- the cross-section's capacity increases with the increase in the concrete's strength in the same proportion between 0.1 to 0.7 , but especially in the region $0.2 \leq \mathrm{P} / \mathrm{P} 0 \leq 0.5$ around the balanced point; - the section's capacity increases with the increase in the steel ratio over the length of the curves;

- the section capacity decreases when the angle of loading increases over the curve, especially in the region of tension control and until $\mathrm{P} / \mathrm{P}_{0}=0.6$, over this value the resistance capacity is the same for the different angles. For all the experiment plans, the calculated capacity factors $\mathrm{K}$ for the different parameters selected and as a function of the axial load level are depicted in Figs. 2-4. Nine typical results of the strength capacity factor $\mathrm{K}$ calculated with 3 ratios, 3 angles and 3 types of concrete with a range of axial loads equal to $0,1 \mathrm{P}_{0}$ to $0,7 \mathrm{P}_{0}$ are obtained.

Figures 4 to 6 show that the strength capacity factor K:

- Decreases for large values of compressive strength, especially in the region of tension control $\mathrm{P} \leq 0.4 \mathrm{P}_{0}$. In the compression

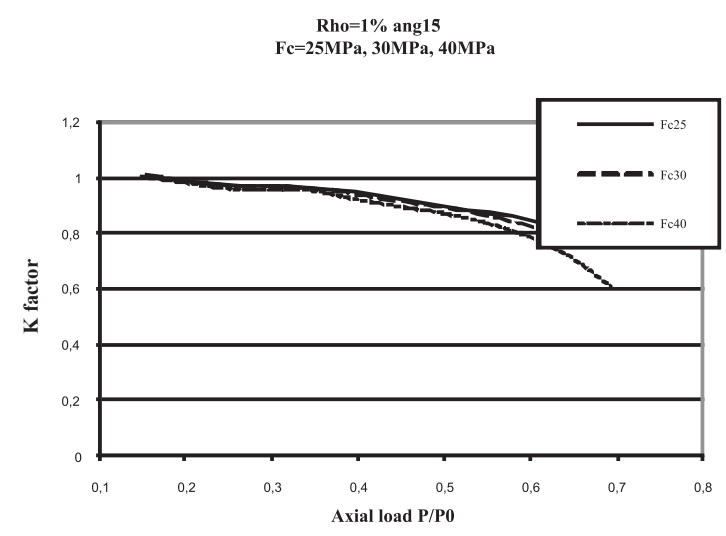

Fig. 4 Variation of K factor in accordance with concrete compression strength.

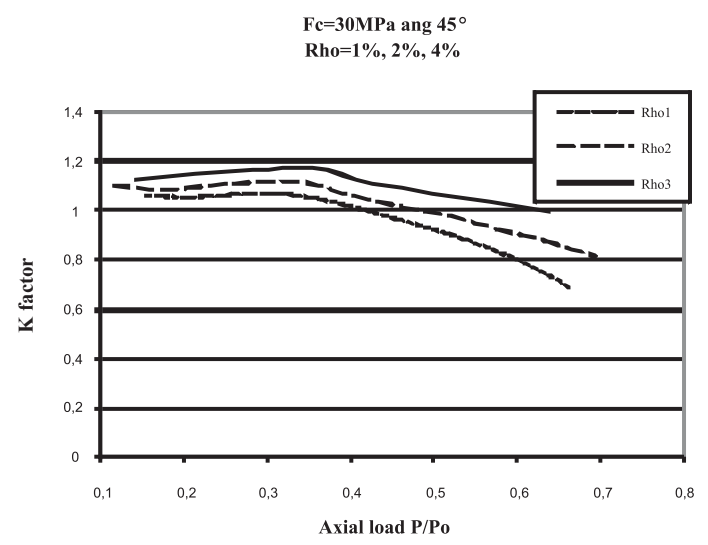

Fig. 5 Variation of $K$ factor in accordance with the steel ratio.

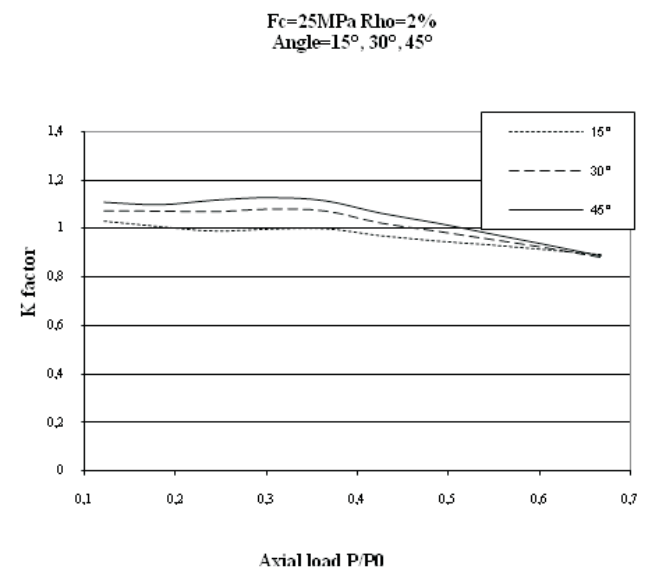

Fig. 6 Variation of $K$ factor in accordance with the loading angle. 
Tab. 2 Values of coefficients.

\begin{tabular}{|ccccccc|}
\hline $\mathbf{a}_{\mathbf{1}}$ & $\mathbf{a}_{\mathbf{2}}$ & $\mathbf{a}_{\mathbf{3}}$ & $\mathbf{a}_{\mathbf{4}}$ & $\mathbf{a}_{\mathbf{5}}$ & $\mathbf{a}_{\mathbf{6}}$ & $\mathbf{a}_{\mathbf{7}}$ \\
\hline 0,002271 & 0,009508 & 0,796264 & 0,006587 & 0,000005 & $-0,010319$ & $-1,177950$ \\
\hline $\mathbf{a}_{\mathbf{8}}$ & $\mathbf{a}_{\mathbf{9}}$ & $\mathbf{a}_{\mathbf{1 0}}$ & $\mathbf{a}_{\mathbf{1 1}}$ & $\mathbf{a}_{\mathbf{1 2}}$ & $\mathbf{a}_{\mathbf{1 3}}$ & $\mathbf{a}_{\mathbf{1 4}}$ \\
\hline$-0,000022$ & 0,000268 & $-0,010901$ & $-0,000054$ & 0,126399 & 0,000725 & $-0,007453$ \\
\hline
\end{tabular}

Tab. 3 Comparison with experimental results Hsu [23].

\begin{tabular}{|c|c|c|c|c|c|}
\hline $\begin{array}{l}\text { Experimental } \\
\text { investigation }\end{array}$ & $\begin{array}{c}\text { Column } \\
\text { specimen }\end{array}$ & $\begin{array}{l}\begin{array}{l}\text { Values } \\
\text { from }\end{array} \\
\text { Tests } \\
\mathbf{K}_{\text {test }} \\
\end{array}$ & $\begin{array}{c}\begin{array}{c}\text { Values } \\
\text { from }\end{array} \\
\text { Formula } \\
\mathbf{K}_{\mathrm{K}} \\
\end{array}$ & $\begin{array}{c}\text { Ratio } \\
\mathbf{K}_{\text {test }} / \mathbf{K}_{\mathbf{K}}\end{array}$ & $\begin{array}{c}\text { Error } \\
\%\end{array}$ \\
\hline \multicolumn{6}{|c|}{ Tension Control } \\
\hline \multirow{4}{*}{$H_{\mathrm{su}}$} & $\mathrm{U}-1$ & 1,025 & 1,102 & 0,930 & 7 \\
\hline & $\mathrm{U}-2$ & 1,024 & 1,122 & 0,913 & 9 \\
\hline & $\mathrm{U}-3$ & 1,015 & 1,138 & 0,892 & 11 \\
\hline & $\mathrm{U}-6$ & 0,859 & 0,912 & 0,942 & 6 \\
\hline \multirow{5}{*}{ Ramamurthy } & B-3 & 1,061 & 1,081 & 0,98 & 2 \\
\hline & B-4 & 1,086 & 1,095 & 0,992 & 0 \\
\hline & B-7 & 1,032 & 1,123 & 0,919 & 8 \\
\hline & B-8 & 1,03 & 1,151 & 0,895 & 10 \\
\hline & & & & average & $7 \%$ \\
\hline \multicolumn{6}{|c|}{ Compression Control } \\
\hline \multirow{3}{*}{$H_{\mathrm{su}}$} & S-1 & 1,198 & 1,092 & 1,097 & 10 \\
\hline & $\mathrm{S}-2$ & 1,118 & 1,084 & 1,031 & 3 \\
\hline & U-4 & 1,047 & 1,148 & 0,912 & 9 \\
\hline \multirow{2}{*}{ Ramamurthy } & B-1 & 0,97 & 0,995 & 0,975 & 2 \\
\hline & B-6 & 1,063 & 1,151 & 0,923 & 8 \\
\hline \multirow{9}{*}{$\begin{array}{l}\text { Heimdahl and } \\
\text { Bianchini }\end{array}$} & BR-3 & 1,108 & 1,059 & 1,046 & 5 \\
\hline & BR-4 & 1,173 & 1,059 & 1,107 & 11 \\
\hline & CR-3 & 1,164 & 1,131 & 1,026 & 3 \\
\hline & CR-4 & 1,184 & 1,134 & 1,044 & 4 \\
\hline & ER-1 & 0,946 & 1,042 & 0,907 & 9 \\
\hline & ER-2 & 1,09 & 1,055 & 1,033 & 3 \\
\hline & Fr-1 & 1,054 & 1,124 & 0,938 & 6 \\
\hline & Fr-2 & 1,13 & 1,154 & 0,979 & 2 \\
\hline & & & & average & $6 \%$ \\
\hline
\end{tabular}

control region, the factor decreases proportionally to large axial load values;

- Increases with large values of the steel ratio, but the values of $\mathrm{K}$ are lower in the region of compression control;

- Increases with large values of a loading angle, especially in the region of tension control.
In order to determine a reasonable regression formula, the effect of each design variable was studied, Figs. 4-6. Since the coefficients are gradually increased or decreased according to changes in each design variable and represent a nonlinear characteristic, a second order polynomial is assumed in terms of the design variables. The regression formula represented in Eq. 4 is finally selected for the capacity factor $\mathrm{K}$ :

$\mathrm{K}=\mathrm{a}_{0}+\mathrm{a}_{1} f^{\prime}{ }_{c}+\mathrm{a}_{2} \rho_{s}+\mathrm{a}_{3}\left(\frac{P}{P_{0}}\right)+\mathrm{a}_{4} \alpha+\mathrm{a}_{5} f^{\prime}{ }^{\prime}{ }^{\mathrm{c}}+\mathrm{a}_{6} \rho_{s^{\mathrm{c}}}+\mathrm{a}_{7}\left(\frac{P}{P_{0}}\right)^{2}+$

$\mathrm{a}_{8} \alpha^{2}+\mathrm{a}_{9} f^{\prime} c \rho_{s}+\mathrm{a}_{10} f^{\prime}{ }_{c}\left(\frac{P}{P_{0}}\right)+\mathrm{a}_{11} f^{\prime} c \alpha+\mathrm{a}_{12} \rho_{s}\left(\frac{P}{P_{0}}\right)+\mathrm{a}_{13} \rho_{s} \alpha+$

$\mathrm{a}_{14} \alpha\left(\frac{P}{P_{0}}\right)$

Where $\mathrm{f}_{\mathrm{c}}{ }_{\mathrm{c}}$ is the compressive strength of concrete $(\mathrm{MPa}), \mathrm{P} / \mathrm{P}_{0}$ the loading level of the axial force, $\rho_{\mathrm{s}}$ the steel ratio $\left(100 . \mathrm{A}_{\mathrm{st}} / \mathrm{A}_{\mathrm{c}}\right)$ and $\alpha$ the loading angle $\left(\alpha^{\circ}\right)$, the variables take the values:

\section{SHORT COLUMNS}

An experimental analysis is carried out in order to compare the numerical results obtained by the proposed formula with the experiment's results. For this purpose, a comparison of the capacity factor $(\mathrm{K})$ is calculated with the proposed formula and those of tests for the specimens selected. Table 3 shows the comparison with the experiment results in Hsu [1988]; it appears clearly that the proposed formulation gives good results: an error of $7 \%$ for the specimens governed by tension control and $6 \%$ for the specimens governed by compression control, with a deviation of $3 \%$.

\section{SLENDER COLUMNS}

According to the ACI 318-99 provisions for the design of slender columns, strength is defined as the cross-section strength; on the other hand, the applied external moment is magnified due to second order effects, i.e., the moment magnification method is used. 


\subsection{Cross-section strength}

For design purposes, when a member is subjected to an axial load $\mathrm{P}$ and moment $\mathrm{M}$, it is usually convenient to replace the axial load and moment with an equal load $\mathrm{P}$ applied at eccentricity $\mathrm{e}=\mathrm{M} / \mathrm{P}$. The computation of the design strength is then obtained through a strain compatibility analysis. The actual compressive stress distribution is replaced by an equivalent rectangular distribution. In computing the value of $\mathrm{P}$ and $\mathrm{M}$, which produce the state of incipient failure, the width of the stress block is taken as $0,85 f^{\prime}{ }_{c}$ and the depth is a $=\beta_{1}$. $\mathrm{c}$ (c is the depth of the neutral axis). The factor $\beta_{1}$ is given by (with the concrete compressive strength $\mathrm{f}_{\mathrm{c}}$, given in $\mathrm{MPa}$ ):

$\beta_{1}=1.09-0.008 \mathrm{f}_{\mathrm{c}}$

With: $0.65 \leq \beta_{1} \leq 0.85$

The solution of the equations stating the equilibrium between the external and internal forces as well as the external and internal moments, within the constraints of strain compatibility, determines the nominal axial load $\mathrm{P}_{\mathrm{n}}$, which can be applied at an eccentricity $\mathrm{e}$ for any eccentrically loaded column.

\subsection{Magnified moments}

For a short column, the moment magnification due to slenderness effects is negligibly small; on the other hand, if the column is sufficiently slender, the maximum moment acting on the column increases nonlinearly as $\mathrm{P}$ increases. For the same externally applied moment $\mathrm{M}$, the strength of the slender column is reduced as compared to the stocky column.

The ACI 318-99 specifies that axial loads and end moments in columns may be determined by a conventional elastic frame analysis. The member is then to be designed for that axial load and a simultaneous magnified column moment. The ACI 318-99 equation for a magnified moment $\mathrm{M}_{\mathrm{c}}$ for columns in non-sway frames is:

$\mathrm{M}_{\mathrm{c}}=\delta_{\mathrm{ns}} \cdot \mathrm{M}_{2}$

the non-sway moment magnification factor $\delta_{\mathrm{ns}}$ is given by:

$\delta_{\mathrm{ns}}=\mathrm{C}_{\mathrm{m}} /\left(1-\mathrm{P}_{\mathrm{u}} / \varphi \mathrm{P}_{\mathrm{c}}\right) \geq 1$

where $\mathrm{M}_{2}=$ the larger factored end moment; $\mathrm{C}_{\mathrm{m}}=$ equivalent uniform moment diagram factor $\left(\mathrm{C}_{\mathrm{m}}=1\right.$ for the case of supports with equal bending at both ends: pure curvature);

$\mathrm{P}_{\mathrm{u}}=$ factored axial load acting on the column; $\varphi=$ capacity reduction factor ( $\varphi=1$ to perform this comparative analysis, which is designed to consider the inevitable random variability of the materials); $\mathrm{P}_{\mathrm{c}}=$ the critical buckling load given by:

$\mathrm{P}_{\mathrm{c}}=\pi^{2} \mathrm{EI} /\left(\mathrm{kl}_{\mathrm{u}}\right)$

Where: $\mathrm{EI}=$ effective rigidity;

\subsection{Magnified moments}

For a short column, the moment magnification due to slenderness effects is negligibly small; on the other hand, if the column is sufficiently slender, the maximum moment acting on the column increases nonlinearly as $\mathrm{P}$ increases. For the same externally applied moment $\mathrm{M}$, the strength of the slender column is reduced as compared to the stocky column. The ACI 318-99 specifies that axial loads and end moments in columns may be determined by a conventional elastic frame analysis. The member is then to be designed for that axial load and a simultaneous magnified column moment. The ACI 318-99 equation for a magnified moment $\mathrm{M}_{\mathrm{c}}$ for columns in non-sway frames is:

$\mathrm{M}_{\mathrm{c}}=\delta_{\mathrm{ns}} \cdot \mathrm{M}_{2}$

The non-sway moment magnification factor $\delta_{\mathrm{ns}}$ is given by:

$\delta_{\mathrm{ns}}=\mathrm{C}_{\mathrm{m}} /\left(1-\mathrm{P}_{\mathrm{u}} / \varphi \mathrm{P}_{\mathrm{c}}\right) \geq 1$

Where $\mathrm{M}_{2}$ is the larger factored end moment, $\mathrm{C}_{\mathrm{m}}$ the equivalent uniform moment diagram factor $\left(\mathrm{C}_{\mathrm{m}}=1\right.$ for the case of supports with equal bending at both ends: pure curvature), $\mathrm{P}_{\mathrm{u}}$ is the factored axial load acting on the column, $\varphi$ the capacity reduction factor $(\varphi=1$ to perform this comparative analysis, which is designed to consider the inevitable random variability of the materials) and $\mathrm{P}_{\mathrm{c}}$ is the critical buckling load given by:

$\mathrm{P}_{\mathrm{c}}=\pi^{2} \mathrm{EI} /\left(\mathrm{k} \mathrm{u}_{\mathrm{u}}\right)$

Where: $\mathrm{EI}=$ effective rigidity;

\subsection{Computer analysis of reinforced concrete columns tested by Dundar et al.}

Dundar, et al. have tested [23] fifteen (15) reinforced concrete columns, twelve specimens of square tied columns and three L-shaped sections. The cross section details and dimensions of each specimen are shown in the Table 3 . The reinforced concrete column specimens were cast horizontally inside a formwork in 


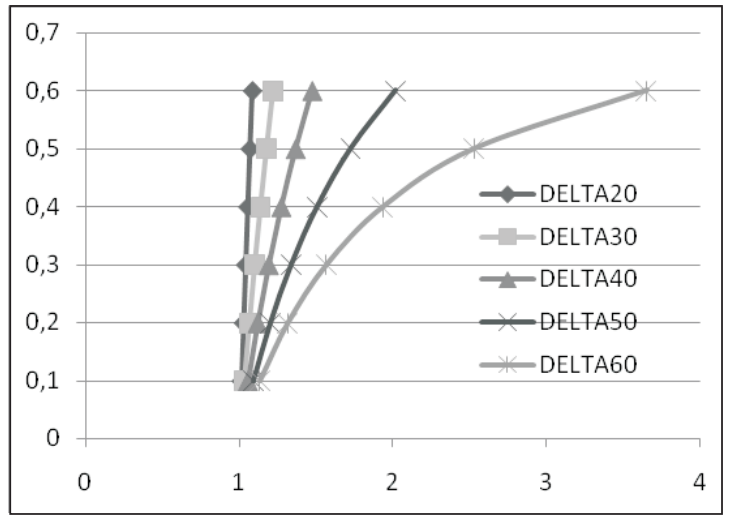

Fig. 7 Variation of $\delta$ factor in accordance with slenderness.

Structural Laboratory at Cukurova University, Adana, Algeria. The longitudinal reinforcement consisted of $6 \mathrm{~mm}$ and $8 \mathrm{~mm}$ diameter deformed bars with a yield strength of 630 and $550 \mathrm{MPa}$, respectively. Lateral reinforcements were arranged using $6 \mathrm{~mm}$ and $6.5 \mathrm{~mm}$ diameter deformed reinforcing bars with a yield strength of $630 \mathrm{MPa}$ for the specimens. The parameters of the specimens and the results are presented in Table 4. The stress-strain model CEC [26] is the same one is used for the determination of the capacity factor $\mathrm{K}$. The reinforced concrete column specimens were tested with pinned conditions at both ends under a short-term axial load and biaxial bending. These specimens were also analyzed for their ultimate strength capacities using a computer program. In the ultimate strength analysis, various stress-strain models and the experimental stress-strain relationships obtained from the cylinder

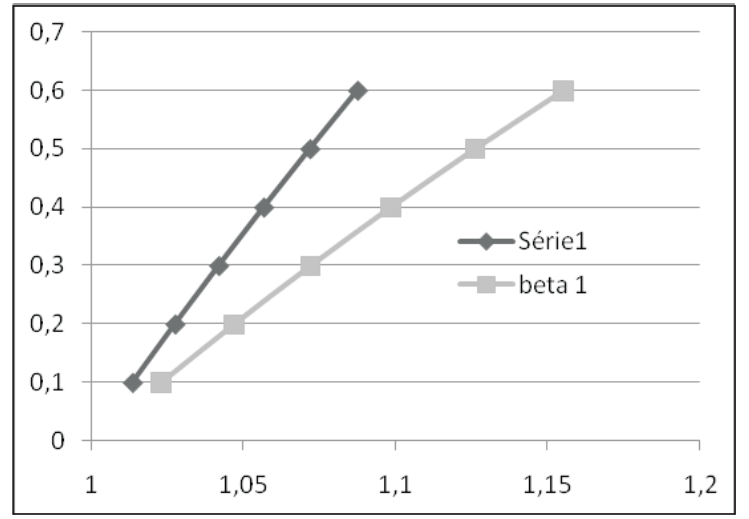

Fig. 8 Variation of $\delta$ factor in accordance with the value of $\beta_{d}$.

specimens of the columns by the authors were used for the concrete compression zone in order to compute the theoretical ultimate strength capacity and to compare it with the experimental results of the column specimens. A good degree of agreement was obtained between the theoretical results according to each of the concrete stress-strain models and the experimental results. The mean ratios of the comparative results indicate that the shape of the concrete stress-strain relationship has little effect on the ultimate strength capacity of the column members; on the other hand, the maximum permissible strain plays the most important role on the ultimate strength capacity.

These columns are then solved by the proposed method for the ultimate strength analysis using the parabola-rectangle defined by the EC2, which is applied to obtain the capacity factor of the section

Tab. 4 Specimen details of $R C$ columns.

\begin{tabular}{|c|c|c|c|c|c|c|c|c|}
\hline Specimen & $\underset{(\mathrm{mm})}{L}$ & $\begin{array}{c}f_{\mathrm{c}} \\
(\mathbf{M P a})\end{array}$ & $\underset{(\mathrm{mm})}{e_{\mathrm{x}}}$ & $\begin{array}{c}e_{\mathrm{y}} \\
(\mathrm{mm})\end{array}$ & $\begin{array}{c}\Phi / \mathrm{s} \\
(\mathrm{mm} / \mathrm{cm}) \\
\text { lateral }\end{array}$ & $\begin{array}{c}\text { Ratio } \\
\rho=\mathbf{A}_{\mathrm{s}} / \mathbf{A}_{\mathrm{g}} \\
\%\end{array}$ & $\begin{array}{l}\text { Ntest } \\
(\mathbf{k N})\end{array}$ & CEC \\
\hline $\mathrm{C} 1$ & 870 & 19.18 & 25 & 25 & $6 / 12.5$ & 1.13 & 89 & 88.95 \\
\hline $\mathrm{C} 2$ & 870 & 31.54 & 25 & 25 & $6 / 15$ & 1.13 & 121 & 126.78 \\
\hline $\mathrm{C} 3$ & 870 & 28.13 & 25 & 25 & $6 / 10$ & 1.13 & 125 & 116.51 \\
\hline $\mathrm{C} 4$ & 870 & 26.92 & 30 & 30 & $6 / 8$ & 1.13 & 99 & 93.57 \\
\hline $\mathrm{C} 5$ & 870 & 25.02 & 30 & 30 & $6 / 10$ & 1.13 & 94 & 88.83 \\
\hline C11 & 1300 & 32.27 & 35 & 35 & $6.5 / 10.5$ & 2.0 & 104 & 88.81 \\
\hline $\mathrm{C} 12$ & 1300 & 47.86 & 40 & 40 & $6.5 / 10.5$ & 2.0 & 95 & 91.39 \\
\hline $\mathrm{C} 13$ & 1300 & 33.10 & 35 & 35 & $6.5 / 10.5$ & 2.0 & 98 & 90.00 \\
\hline C14 & 1300 & 29.87 & 45 & 45 & $6.5 / 12.5$ & 2.0 & 58 & 63.02 \\
\hline $\mathrm{C} 21$ & 1300 & 31.7 & 40 & 40 & $6.5 / 10.5$ & 0.89 & 238 & 233.41 \\
\hline $\mathrm{C} 22$ & 1300 & 40.76 & 50 & 50 & $6.5 / 10.5$ & 0.89 & 199 & 208.83 \\
\hline $\mathrm{C} 23$ & 1300 & 34.32 & 50 & 50 & $6.5 / 10.5$ & 0.89 & 192 & 189.38 \\
\hline
\end{tabular}


$\mathrm{K}$; then the ultimate bending moment of the section $\mathrm{M}_{\mathrm{UT}}$ is obtained. The ultimate moment of the slender member $\mathrm{M}_{\mathrm{UMS}}$ is computed by using the magnification factor. The theoretical results obtained for the maximum resisting moment capacity as well as the test results are presented in Table 6 for comparison.

A good degree of accuracy has been obtained between the theoretical and the experimental results; an average ratio of 1.06 with a variation coefficient of $9 \%$ was achieved.

\section{CONCLUSIONS}

An iterative numerical procedure for the strength analysis and design of short and slender reinforced concrete columns which square cross sections under biaxial bending and an axial load by using the EC2 stress-strain model is presented in this paper. The computational procedure takes into account the nonlinear behavior of the materials (i.e., concrete and reinforcing bars) and includes the second order effects due to the additional eccentricity of the applied axial load by the Moment Magnification Method.

The capability of the proposed method and its formulation has been tested by means of comparisons with the experimental results reported by some authors. The theoretical and experimental results show that a good degree of accuracy has been obtained; an average ratio (proposed to test) of 1.06 with a deviation of $9 \%$ has been achieved. On the other hand, the compressive strength of concrete and its corresponding compressive strain are the most effective parameters of the ultimate strength capacity of column members. Consequently, the proposed formulation can simulate the behavior of slender members under biaxial loading with a good degree of accuracy.

\section{REFERENCES}

[1] Furlong RW. Concrete columns under biaxially eccentric thrust. ACI Journal October 1979:1093-118.

[2] Brondum-Nielsen T. Ultimate flexural capacity of fully prestressed, partially prestressed, arbitrary concrete sections under symmetric bending. ACI Journal 1986;83:29-35.

[3] Hsu CTT. Biaxially loaded L-shaped reinforced concrete columns. Journal of Structural Engineering ASCE 1985;111(12):2576-95.

[4] Hsu CTT. Channel-shaped reinforced concrete compression members under biaxial bending. ACI Structural Journal 1987;84:201-11.

[5] Dundar C. Concrete box sections under biaxial bending and axial load. Journal of Structural Engineering 1990;116:860-5.

[6] Rangan BV. Strength of reinforced concrete slender columns. ACI Structural Journal 1990;87(1):32-8.

[7] Building code requirements for structural concrete (ACI 31899). Detroit (MI): American Concrete Institute (ACI); 1999.

[8] Dundar C, Sahin B. Arbitrarily shaped reinforced concrete members subjected to biaxial bending and axial load. Computers and Structures 1993; 49: 643-62.

[9] Whitney CS. Plastic theory of reinforced concrete design. Transactions, ASCE 1940; 107:251-60.

[10] Rodriguez JA, Aristizabal-Ochoa JD. Biaxial interaction diagrams for short RC columns of any cross SECTION. Journal of Structural Engineering 1999; 125(6):672-83.
[11] Fafitis A. Interaction surfaces of reinforced-concrete sections in biaxial bending. Journal of Structural Engineering 2001; 127(7):840-6.

[12] Hong HP. Strength of slender reinforced concrete columns under biaxial bending. Journal of Structural Engineering 2001;127(7):758-62.

[13] Saatcioglu M, Razvi SR. High-strength concrete columns with square sections under concentric compression. Journal of Structural Engineering 1998;124(12):1438-47.

[14] Furlong RW, Hsu CTT, Mirza SA. Analysis and design of concrete columns for biaxial bending- overview. ACI Structural Journal 2004;101(3):413-23.

[15] Mirza SA. Parametric study of composite column strength variability. Journal of Constructional Steel Research 1989;14:121-37.

[16] Lachance L. Ultimate strength of biaxially loaded composite sections. Journal of Structural Division, ASCE 1982;108:231329.

[17] Chen SF, Teng JG, Chan SL. Design of biaxially loaded short composite columns of arbitrary section. Journal of Structural Engineering 2001;127(6):678-85.

[18] Sfakianakis MG. Biaxial bending with axial force of reinforced, composite and repaired concrete sections of arbitrary shape by fiber model and computer graphics. Advances in Engineering Software 2002; 33:227-42. 


\section{REFERENCES}

[19] Kent DC, Park R. Flexural members with confined concrete. Journal of Structural Division ASCE 1971; 97(7):1969-90.

[20] Sheikh SA, Uzumeri SM. Analytical model for concrete confinement in tied columns. Journal of Structural Division ASCE 1982;108(12): 2703-22.

[21] Saatcioglu M, Razvi SR. Strength and ductility of confined concrete. Journal of Structural Engineering 1992; 118(6):1590 607.

[22] Chung HS, Yang KH, Lee YH, Eun HC. Stress-strain curve of laterally confined concrete. Engineering Structures 2002; 24:1153-63.
[23] Dundar C, Tokgoz S, Tanrikulu A.K, Baran T, Behavior of reinforced and concrete-encased composite columns subjected to biaxial bending and axial load. Building and environment 2007.

[24] RPA 2003, rčglement parasismique algérien (Algerian Code, in French).Ministčre de l'Habitat, Algeria.

[25] Hsu C.T.T., Analysis and Design of Square and Rectangular Columns by Equation of Failure Surface, ACI Structural Journal, Technical paper, title no 85-S20, 1988, pp 167-179.

[26] Commission of the European Communities (CEC). Design of composite steel and concrete structures. Brussels: Eurocode 4; 1984. 